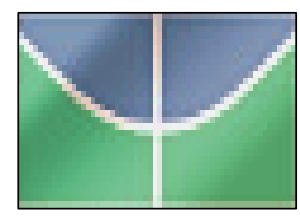

UNIVERSIDADE DE BRASÍLIA

DEPARTAMENTO DE LINGUÍSTICA, LÍNGUAS CLÁSSICAS E PORTUGUÊS LIP

DISCIPLINA: PROJETO DE CURSO

PROFESSORA DOUTORA: ELOISA NASCIMENTO SILVA PILATI

REVISÃO DE TEXTOS COMO METODOLOGIA DE ENSINO DE LÍNGUA PORTUGUESA

MARÍLIA GONÇALVES LOPES

Brasília 
Marília Gonçalves Lopes - matrícula: 09/0010825

(lilaglopes@gmail.com.br)

\section{REVISÃO DE TEXTOS COMO METODOLOGIA DE ENSINO DE LÍNGUA PORTUGUESA}

Trabalho apresentado ao Departamento de Linguística, Línguas Clássicas e Português (LIP), da Universidade de Brasília, como requisito para conclusão da disciplina de Projeto de Curso.

Orientadora: Professora Doutora Eloisa Nascimento Silva Pilati

Brasília 


\section{RESUMO}

O presente artigo apresenta propostas sobre a adoção de práticas de revisão textual como metodologia de ensino da língua portuguesa. As propostas são baseadas em diversas temáticas tais como: a diferenciação semântica entre os termos "revisão" e "correção textual", a discussão sobre a importância dos estudos e critérios de revisão de textos para o ensino escolar, a influência da consciência morfossintática na aprendizagem de língua portuguesa e na prática de revisão, a necessidade de preparação do professor para que ensine tal atividade. No intuito de orientar o trabalho do professor, apresentam-se critérios que podem ser utilizados para o ensino de revisão de texto, criando etapas para a realização da revisão, além demonstrar um exemplo de dinâmica pedagógica para suscitar nos alunos o interesse e reconhecimento da necessidade da revisão textual.

Palavras-chave: Revisão. Correção. Método de ensino. Aluno-Autor. Professor. Consciência morfossintática. 


\section{SUMÁRIO}

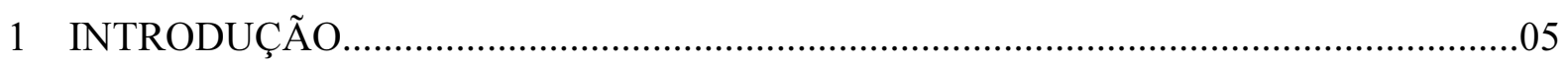

2 A REVISÃO DE TEXTO COMO PRÁTICA DE ENSINO_..................................................

3 DIFERENCIAÇÃO SEMÂNTICA ENTRE REVISÃO E CORREÇÃO

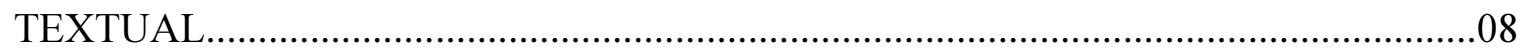

4 INFLUÊNCIA DE CONSCIÊNCIA MORFOSSINTÁTICA NA

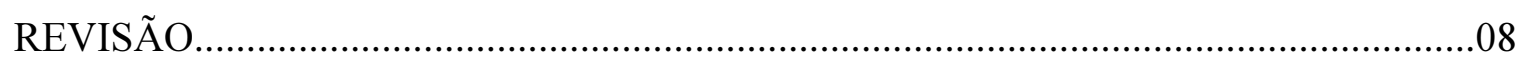

5 FUNÇÃO DO PROFESSOR NO ENSINO DE REVISÃO DE

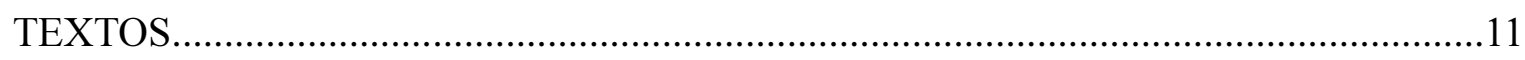

6 PRÁTICAS DE REVISÃO TEXTUAL COMO METODOLOGIA DE ENSINO DA

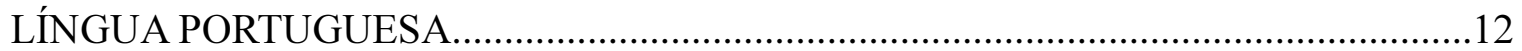

7 TÉCNICAS DE ENSINO DE REVISÃO DE TEXTO....................................................13

8 EXEMPLO DE DINÂMICA DE REVISÃO DE TEXTO_.................................................16

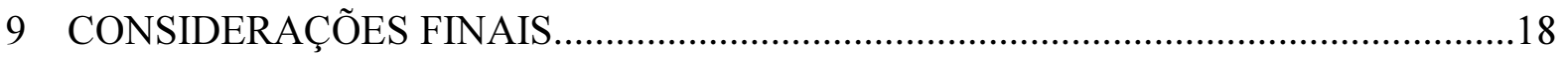

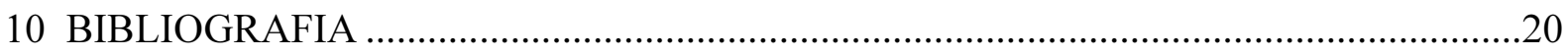




\section{INTRODUÇÃO}

A presente pesquisa ${ }^{1}$ estuda a revisão de textos como uma técnica de ensino de língua portuguesa, para tanto procurar-se-á entender as bases científicas que apoiam esse ensino, a inter-relação da revisão com as metodologias de ensino e a necessidade de tal conhecimento para auxiliar na formação de um aluno-autor mais consciente e crítico sobre seu escrito.

Os objetivos da pesquisa serão:

1. Entender necessidade da revisão de texto como prática de ensino;

2. Diferenciar semanticamente revisão de correção textual;

3. Analisar influência de consciência morfossintática na revisão;

4. Discutir função e preparação do professor para a transmissão de tal conhecimento;

5. Explicitar técnicas de ensino de revisão de texto para orientar o trabalho do professor quanto à forma ideal de ensinar revisão;

6. Desenvolver critérios para a adoção da revisão textual como metodologia de ensino da Língua Portuguesa.

A principal motivação para os estudos de revisão de texto como metodologia de ensino é a intenção de formar escritores conscientes e críticos, que pensem tecnicamente no ato da escrita, que analisem as palavras e conceitos que abordam em seu escrito, que revisem o que escrevem, que critiquem e julguem a compreensão e estética de seu próprio texto.

Um aluno que tem conhecimento e entendimento de seu próprio texto, provavelmente, terá mais facilidade em se incorporar ao meio social e profissional, uma vez que saberá desenvolver melhor seu pensamento, evitar as dificuldades para a interpretação do leitor, escrever de acordo com as normas e produzirá um texto mais claro para o leitor final (destinatário), a partir da tipologia textual adequada, assim contemplando requisitos importantes para escritos coerentes e bem estruturados.

O aluno, com melhor conhecimento de seu texto, também será capaz de identificar suas dificuldades e habilidades, cumprindo de forma mais eficiente alguns dos objetivos

1 A presente pesquisa está vinculada ao projeto de programa de bolsas do REUNI (Edital DEG 06/2011), que procura proporcionar "aos estudantes do Curso de Letras (diurno e noturno) da Universidade de Brasília a possibilidade de realizarem estudos complementares na área de gramática da língua portuguesa e de outras línguas modernas, por meio da constituição de um grupo de estudos". Esse projeto busca, por meio de grupos de estudos, oferecer aos estudantes um espaço para desenvolver estudos de fenômenos linguísticos como uma forma de orientar e desenvolver a formação desses alunos de Letras para a prática docente. 
tratados no livro dois dos Parâmetros curriculares nacionais: língua portuguesa (1997).

Os PCNs visam orientar os educadores com procedimentos didáticos que auxiliem a produção continuada de produção de texto dentro da escola, para tanto, elencam alguns pontos relevantes, como:

- Apresentar aos alunos textos escritos de boa qualidade, os quais servirão de referência de escrita para eles.

- Solicitar aos alunos que produzam textos, mesmo antes de eles serem capazes de grafá-los.

- Explorar o diálogo entre professores e alunos, pois, por meio de conversas, podem ser externadas as dificuldades sentidas quanto à produção textual.

- Trabalhar a produção textual em grupo, de modo que, desempenhado diferentes papéis discursivos, os alunos possam produzir, grafar e revisar, desenvolvendo, numa atividade colaborativa, competência para depois, sozinhos, serem capazes de realizar todos os procedimentos que envolvem a produção textual.

$[\ldots]$

Segundo os PCNs, a revisão de textos passa, portanto, a ter um papel fundamental na prática de produção. Trata-se de uma competência que precisa ser sistematicamente ensinada, de modo que, cada vez mais, assuma sua real função: monitorar todo o processo de produção textual desde o planejamento. (COÊLHO, 2009:8)

A partir da perspectiva explicitada na citação, percebe-se a ideia de que o aluno deverá ser eficiente no papel de produtor, leitor ou revisor de seu texto, ou seja, o aluno revisará seu texto desde o momento da seleção de ideias até os aspectos finais. De tal forma, esse texto apresenta métodos e técnicas de ensino sobre o tema revisão de textos no ensino de Língua Portuguesa.

\section{A REVISÃO DE TEXTO COMO PRÁTICA DE ENSINO}

A produção textual requer de seu escritor uma gama extensa de conhecimento sobre forma estrutural do texto, entendimento de regras gramaticais, de vocabulário, do tema a ser escrito entre outros. Assim, o texto deve ser um conceito explanado através de um conjunto de palavras e frases articuladas e com significado.

É importante que se entenda a necessidade de se preparar os alunos em relação a sua formação intelectual, para que saibam o que revisar e como revisar. Tal necessidade pode ser comparada com a ideia argumentada por estudiosos da revisão textual, que ressaltam a 
necessidade de preparação intelectual para se qualificar o profissional de revisão. Segundo Arezio (apud NETO, 2008:26):

[...] as constantes divergências de crenças religiosas e a falsa interpretação dos textos sacros deram lugar a discussões e controvérsias. Daí a necessidade de formarem um corpo de revisão, entre os homens de maior fama intelectual e erudição comprovada, para fazerem a correção ou revisão dos manuscritos antigos, dando-lhes nova forma, alterando-lhes os períodos, de modo que as subsequentes edições saíssem isentas daqueles senões.

A partir da citação, retirada de um manual de revisão profissional, percebe-se a importância de analisar um texto com olhos críticos e pontuais às incorreções e imperfeiçoes do escrito, assim, desde antigamente, intuiu-se a necessidade de um revisor preparado intelectualmente para revisar e corrigir os escritos antigos, tal como os produzidos para leitura posterior de um leitor final.

Para construir um bom texto, é necessário que o autor além de escrever suas ideias, também faça a revisão de seu texto, no intuito de sanar dúvidas, incoerências semânticas, erros gramaticais, da sequência lógica. Logo "revisar é ir além de corrigir, porque pode significar também alterar o texto em aspectos que não estão "errados" (...)" (MEC, 1998: 5-6).

De tal modo, percebe-se que a produção textual e a revisão textual são procedimentos distintos, pois o primeiro se mostra como o ato de criar e explanar as ideias do autor, já o segundo se revela como uma visão crítica e analítica feito pelo autor-revisor. Assim, percebese que a revisão de um texto visa garantir a qualidade e o bom entendimento deste, através de melhorias nos aspectos gramaticais, estilísticos, estruturais e semânticos auxiliando a formação de autor-revisor consciente de seu texto.

re.vi.são

Substantivo feminino.

1.Ato ou efeito de rever ${ }^{1}$.

2.Novo exame.

3.Edit. Arte, ato ou efeito de rever ou revisar.

4.Edit. Local onde trabalha(m) revisor(es) em editoras, etc. [P1.: -sões.] re.vi.sar

Verbo transitivo direto.

Ler (texto a ser publicado, etc.) procurando os erros e assinalando-os.

(FERREIRA, 2004)

A citação, retirada do Dicionário Miniaurélio Eletrônico, confirma a função e as 
atividades exercidas por um revisor textual, destacando a ideia de que revisar é reler um texto atentamente procurando por imperfeições no nível textual (morfologia, sintaxe e semântica) e no nível estético.

\section{DIFERENCIAÇÃO SEMÂNTICA ENTRE REVISÃO E CORREÇÃO TEXTUAL}

A partir de tal noção sobre revisão, pode-se discutir o problema semântico relacionado à colocação dos termos "correção" e "revisão". A colocação de um ou de outro termo parece influenciar a forma com que o professor avaliará o texto. Assim, pode-se subentender que o termo revisão demonstra uma semântica mais próxima da ideia de imparcialidade, objetividade e melhoramento do texto; já o termo correção aparenta ser uma forma mais severa, que busca refazer, apontar erros e problemas no texto, mas sem apresentar formas de repensar as estruturas textuais com incongruências e/ou distorções.

A metodologia de ensino de Língua Portuguesa por meio de revisão é mencionada nos PCN's quanto à distinção do sentido de revisar e corrigir, como se apreende na citação abaixo:

Muitos professores aos quais são apresentados "novos" projetos de ensino se perguntam se, afinal, devem continuar corrigindo ou não. A pergunta, talvez, seja mal posta. Obviamente, um professor não pode esperar que os alunos aprendam sem sua intervenção; afinal, é para "ajudar" que o professor está na aula. O que talvez deva ser novo é o modo de "corrigir". Por isso, aqui se propõe empregar as palavras revisar (revisão) e reescrever (reescrita). (BRASIL, 2008: 5-6)

\section{INFLUÊNCIA DE CONSCIÊNCIA MORFOSSINTÁTICA NA REVISÃO}

Para que o aluno possa produzir e revisar seu texto, como já foi exposto, necessita de certos conhecimentos e habilidades referentes à sua língua. Tal ideia é exposta pelas autoras Guimarães e Paula (2010), que defendem que, para que uma pessoa leia e escreva, ela precisa ter "o domínio de diversas habilidades linguístico-cognitivas relativas a um sistema de escrita. Além disso, várias evidências empíricas têm demonstrado que as habilidades metalinguísticas são também primordiais para a aprendizagem formal da escrita na escola." (2010: 95)

Tanto Guimarães e Paula (2010) quanto Mota (2009) explanam que a escrita representa sons com significados dentro da língua, e que o aluno precisa de conhecimentos fonográficos (relação dos fonemas com os grafemas) e semiográficos (relação unidades gráficas - palavras - com significado), além de compreender a noção de morfema (menor signo linguístico com significado).

Os morfemas são os menores signos linguísticos que encerram um significado: se a palavra "flor" for reduzida a "fl" o significado 
desaparece, pois em português /f1/ não significa nada. Uma palavra pode ser formada de um único morfema (palavra simples, tal como "flor") ou mais morfemas (palavra complexa, tal como, "flores" que significa mais de uma flor). (GUIMARÃES e PAULA, 2010: 95)

Logo, compreende-se que os morfemas, na língua portuguesa, podem ser a base significativa das palavras, que modificam ou ampliam o sentido da sua classe gramatical ou seu significado. Tal conhecimento pode ter particularidades morfológicas que são necessárias para a efetividade do uso da escrita e da fala pelo usuário da língua. Por exemplo, no caso do morfema pode ser dividido em raiz e afixo, a raiz tendo função de significado básico do léxico (livro - raiz: livr-), já os afixos tendo função de derivar (pode mudar a classe gramatical) ou flexionar a palavra.

De tal modo, "a flexão e os morfemas flexionais têm caráter morfossintático, pois cumprem uma exigência de concordância nominal ou verbal, de acordo com a necessidade imposta pela frase." (GUIMARÃES e PAULA, 2010: 96)

Baseando-se em tais conceitos, é possível apreender que tais conhecimentos relativos à morfologia podem ser fundamentais para o desenvolvimento da escrita e o reconhecimento do significado das palavras. O ensino adequado destes temas, quando da alfabetização da criança pode auxiliar significativamente quando do ensino de revisão do texto em séries posteriores.

Tal como se percebe no excerto abaixo:

Os morfemas em português cumprem várias funções na palavra, pois podem constituir sua base essencial, ampliar e modificar seu sentido ou sua classe gramatical, flexioná-la e colocá-la em um contexto sintático, ou mesmo ligar termos em uma sentença. Para utilizar habilmente este conhecimento, é preciso examinar algumas particularidades da morfologia e das habilidades (meta) linguísticas relativas à morfologia, necessárias ao usuário da língua. (GUIMARÃES e PAULA, 2010: 95)

Com base nesta citação, percebe-se que a consciência morfossintática tem papel fundamental no ensino e na aprendizagem das noções gramaticais da língua materna, uma vez que o aluno que tem consciência do seu conhecimento sobre sua língua, as palavras, como elas se formam, se estruturam, seus significados, funções sintáticas, obviamente terá mais facilidade para entender as regras gramaticais e seu efetivo uso na língua e nos textos.

Nota-se a ideia de que a consciência do aluno sobre noções morfossintáticas têm significativa importância no ensino e na aprendizagem da criança quanto a reconhecimento das palavras de sua língua materna, tal como também da forma como tais palavras são 
formadas e aplicadas nas orações. De tal modo, o aluno quando tem consciência das palavras que fala e escreve provavelmente terá mais facilidade em saber qual a sua classe gramatical, seu sentido, sua função sintática, entre outros conceitos.

Uma forma simples de explicitar a efetividade da consciência morfossintática no ensino de gramática, mesmo em séries iniciais seria, por exemplo, no ensino de divisão silábica, pois se o aluno tiver conhecimento sobre como uma palavra é formada, obviamente terá mais facilidade no momento de dividi-la. Por exemplo, se o aluno souber que a palavra 'pedreira' vem da palavra 'pedra' que tem como raiz 'pedr', ele terá menos dificuldade em dividir tal palavra 'pe-drei-ra'; tal como se o aluno, em série mais avançada, tiver conhecimento de sufixo, prefixo, aglutinação, justaposição etc, no qual saberá ao certo tal conhecimento.

Saber os processos de formação da palavra utilizados na separação silábica, também pode ser utilizado na ideia de mudança sintática, na qual o acréscimo de um sufixo pode mudar tanto o sentido quanto classe gramatical de uma palavra, tal como no exemplo da palavra 'feliz' que é um adjetivo, mas se acrescida do sufixo 'mente', e formando a palavra 'felizmente' passará a ser um advérbio.

A consciência morfológica é tratada pelas autoras, Guimarães e Paula (2010), como uma habilidade que possibilita ao autor, por conta própria, pensar e modificar a estrutura morfológica da língua (flexionar, modificar, criar palavras), já a consciência sintática se revelaria como sendo a capacidade de controlar o uso da sintaxe (usar normas gramaticais para produzir e entender uma frase, oração).

[...] sugere-se que a aprendizagem da leitura e da escrita é influenciada tanto pela consciência fonológica quanto pela consciência morfossintática - a qual possibilita a focalização das palavras como categorias gramaticais e a sua adequada posição na construção das frases, aumentando a capacidade de identificação e produção da linguagem escrita. [...] (GUIMARÃES e PAULA, 2010: 97)

Com base na citação acima, entende-se que a consciência sintática é fundamental para compreensão dos alunos sobre como processos sintáticos formais que são utilizados na construção de frases. O conhecimento sintático é essencial, por exemplo, para o entendimento de concordância (nominal e verbal), uma vez que a concordância existe na frase quando as palavras se relacionam sintaticamente, como por meio da flexão (morfológico), assim percebendo-se a importância da inter-relação da sintaxe com a morfologia para a aprendizagem da língua portuguesa em sua forma escrita e formal. 
Mota (2009), por sua vez, apresenta um artigo que apresenta diversos estudos e seus resultados sobre a consciência morfológica, fonológica e morfossintática, alguns pontos de seu texto correspondem com ideia defendida por Guimarães e Paula (2010). Na conclusão de seu texto, a autora considera a possibilidade de a consciência morfológica ter relação com o processo de alfabetização e, ainda, defende a ideia de que a educação do Brasil precisa aprofundar suas pesquisas sobre tais aspectos comentados.

O estudo do desenvolvimento da consciência morfológica e de sua relação com a leitura e escrita vem se constituindo em um importante campo de pesquisa. Há algum consenso entre pesquisadores nesta área de que a consciência morfológica contribui para alfabetização em línguas alfabéticas;

$[\ldots]$

Destaca-se então a importância de estudos que investiguem a relação da consciência morfológica e fonológica com a escrita em diferentes ortografias. Particularmente no português temos um campo fértil para esse tipo de investigação, uma vez que é uma língua bastante regular em termos de correspondência entre letra e som, ao mesmo tempo em que é morfologicamente complexa. (MOTA, 2009: 164-165)

\section{FUNÇÃO DO PROFESSOR NO ENSINO DE REVISÃO DE TEXTOS}

[...] o papel do professor é fundamental. É ele que vai ensinar aos alunos o que é revisar, qual sua importância no processo de produção, de que formas podem ser feitas, em que situações é importante revisar etc. Portanto, a revisão de textos constitui-se um conteúdo procedimental que precisa ser ensinado pois os alunos não aprendem sozinhos e muito menos escrevendo um texto em apenas uma versão. [...] (OLIVEIRA, p. 1)

Um dos objetivos deste trabalho é instruir o profissional da área de educação, sobre como criar metodologias para ensinar aos alunos critérios para avaliar a produção deles, de forma impessoal e eficiente. Pois para que o aluno venha a corrigir seu próprio texto, antes é preciso que ele tenha uma boa conscientização sobre como fazer tal atividade, e para adquirir tal conhecimento é necessário um profissional competente para o ensino dessa metodologia de revisão.

A preparação de um professor de língua portuguesa que ensine critérios de revisão, para auto-avaliação dos textos, deve ser baseada na conscientização de tal profissional sobre o processo de ensino do educando, uma vez que é um procedimento longo, feito por etapas, mas contínuo, assim, o aluno aprenderá no decorrer de seu ensino escolar como revisar cada aspecto do texto. 
Tal ideia de um aprendiz que sabe avaliar é apresentada em um estudo feito por Elizabeth Menegolo e Leandro Menegolo (2005):

[...] O aluno, ao escrever, tem todo um complexo trabalho com a linguagem, para construir-se enquanto sujeito-autor. Não será de uma hora para outra que ele se desconstruirá (enquanto autor) e se reconstruirá como sujeito-avaliador, porque, de certa forma, ele espera que seu texto seja corrigido pelo professor, que é o seu interlocutor. (MENEGOLO, 2005: 76)

Logo é fundamental, que o professor de língua portuguesa focado no ensino de revisão entenda que esta aprendizagem não é um processo imediato, e, sim, o contrário, ao passo que o aluno precisa se adequar primeiramente a ideia de ler e se reconhecer enquanto autor, para depois ter competência para analisar e revisar seu próprio texto, e ainda pensar sobre como o leitor irá interpretar suas ideias.

\section{PRÁticAs de REVISÃO TEXTUAL COMO METODOLOGIA DE ENSINO DA LÍNGUA PORTUGUESA}

[...] a revisão não deve ser vista como um procedimento que está a serviço de tornar o texto perfeito. [...] As situações de revisão que devem ser propostas para os alunos devem ter como objetivo favorecer uma nova possibilidade de interação com o texto - é possível, é preciso, é necessário olhar para um texto que foi escrito pensando em quem irá lê-lo. (OLIVEIRA, p. 3)

Outro intuito deste estudo é entender como as práticas de revisão textuais podem ser úteis e eficientes como metodologia de ensino de língua portuguesa. Para tanto, tem-se por base o livro SkillsBook (livro de habilidades) que é um material didático, usado em escolas americanas e escrito em inglês, direcionado para alunos de ensino fundamental, com a finalidade de ajudá-los a exercitar a edição e revisão de textos, utilizando-se de várias atividades para que o aluno possa desempenhar tal prática. Assim, o aluno além de, por exemplo, aprender o conceito de vírgula e como utilizá-la, também aprenderá como aplicar esse conhecimento no texto-exercício do livro tal como no seu próprio texto.

O SkillsBook (livro de habilidades) que foi desenvolvido pelo grupo de educação de uma divisão da Houghton Mifflin Company Wilmington, em Massachusetts, se mostra como um livro didático que apresenta a prática revisão de texto como uma metodologia de ensino de regras gramaticais.

A partir do exemplo do livro citado, entende-se que, para aplicar nas aulas de língua portuguesa o tema revisão, é preciso utilizar uma metodologia de ensino baseada na exposição 
de conteúdo (aluno precisa de conhecimento prévio para revisar) e também na prática do que foi aprendido pelo educando, para melhorar a compreensão e fixação do conhecimento apresentado (aplicação em revisão de textos).

Assim, por exemplo, o professor de gramática pode ao explicar sua matéria inserir nas atividades de fixação alguma atividade de revisão dos aspectos gramaticais do texto; já um professor de redação ou interpretação de texto pode inserir a revisão textual em atividades onde procurem saber se o texto tem sequência lógica, se é coerente e coeso, se transmite uma mensagem clara, qual o tipo textual do texto segue etc, ou seja, procurar revisar aspectos da linguagem escrita e literária.

O professor de redação pode dar mais ênfase à revisão de texto quando da produção textual de seus alunos, quando pode orientá-los sobre a releitura da redação, a reescritura, o reconhecimento de incoerências e erros gramaticais, mostrando para os alunos-autores que todo esse trabalho deve ser feito juntamente a produção textual.

Se o trabalho do professor for efetivo, provavelmente, estará contribuindo para a formação de um escritor/revisor proficiente, que saberá que a revisão deve ser feita durante todo o processo de escrita, para que se construa um texto claro, objetivo, que transmita a mensagem do autor e que seja livre de falhas gramaticais e semânticas.

\section{TÉCNICAS DE ENSINO DE REVISÃO DE TEXTO}

A partir da experiência relatada do livro SkillsBook, que apresenta uma forma didática e baseada em critérios de se ensinar revisão de texto como um conteúdo escolar, apresenta-se neste artigo uma forma geral de critérios que o professor pode usar para orientar seus alunos sobre como revisar seus escritos.

O ponto inicial para o ensino de revisão de texto é o trabalho do professor como conscientizador da importância de tal atividade, uma vez que o aluno precisa entender a necessidade de realizar a revisão, tal como compreender como isso irá melhorar o seu texto semântico, sintática e esteticamente.

É importante que o professor ao passar uma tarefa de revisão de um texto do próprio aluno, lhe conceda um tempo considerável para que ele possa realizar no mínimo duas leituras do seu texto, com um intervalo de tempo para que este possa analisar o texto com mais impessoalidade e criticidade.

O professor pode ensinar técnicas de revisão utilizando o texto do próprio aluno ou um texto padrão para toda a turma, em ambos os textos, os alunos precisarão ler os textos 
buscando problemas na coesão, na ortografia, na estética, entre outros. Cada problema que o aluno encontrar deverá corrigi-lo e marcar em uma coluna à direita o que ele acredita que seja o problema. Assim, por exemplo, se o aluno leu uma frase e achou um erro na ortografia de uma palavra, ele deve assinalar na coluna a direita que foi corrigido um erro de ortografia naquela frase.

O intuito de o aluno escrever o erro é que ele procure entender o porquê daquele problema sintático, semântico e/ou morfológico não ser aceito pela escrita formal (baseada na gramática tradicional), o porquê que o erro poderia dificultar o entendimento da ideia transmitida no escrito. Assim desenvolvendo no aluno a consciência tanto das estruturas fonológicas, sintáticas e morfológicas da língua quanto importância de se utilizar a norma padrão da língua na escrita para ser bem entendido por outras pessoas com quem se comunique através da forma escrita da língua.

A partir de tais ideias de revisão, desenvolve-se a seguir etapas para a revisão de um texto, com base em critérios para cada etapa, no intuito de elucidar quais pontos do texto devem ser verificados e revisados para que o texto fique adequado de acordo com a gramática e semântica.

$1^{\mathrm{a}}$ etapa - Aspectos semânticos

Nesta etapa o aluno deve ler atentamente o texto procurando analisar o sentido do texto, a sua relação com o tema proposto, com o título do texto, ou seja, verificando se o texto tem uma sequencia lógica das ideias do texto.

Para tanto o aluno precisa revisar os seguintes aspectos:

- Coesão entre as palavras, frases e ideias;

- Coerência das ideias e dos parágrafos;

- Sequencia lógica das ideias e dos parágrafos;

- Relação dos parágrafos, ou seja, um parágrafo ou tema deve ter relação com o parágrafo anterior e posterior.

$2^{\text {a }}$ etapa - Aspectos morfológicos, fonológicos e sintáticos (gramaticais)

Nesta etapa o aluno precisará de mais tempo e esforço, pois ele analisará cada frase do texto, buscando problemas na ortografia, na ordem das palavras, na pontuação, na concordância entre as palavras, na flexão de verbos entre outros. 
Para tanto o aluno precisa revisar os seguintes aspectos:

- Ortografia (ver novo acordo ortográfico);

- Acentuação (cuidado com o trema - novo acordo ortográfico)

- Pontuação (vírgula, ponto final, exclamação, interrogação, travessão, etc);

- Repetição de palavras (utilizar sinonímias);

- Vícios de linguagem (barbarismo, ambiguidade, neologismo, cacófato e outros);

- Conjugação verbal;

- Concordância verbal e nominal;

- Explicitação do sujeito e suas retomadas ao longo do parágrafo;

- Orações coordenadas e subordinadas com sentido dentro do texto;

- Pronome - atentar para o uso e seus referentes;

- Flexão (substantivo: gênero, número e grau; verbo: tempo, número, modo, pessoa e de voz);

- Estrutura da ordem linear da língua, SVO (sujeito, verbo e objeto), atentando para não se separar verbo de predicado, por exemplo.

$3^{\mathrm{a}}$ etapa - Aspectos de padronização e estrutura textual

Nesta etapa o aluno já terá revisado todo o conteúdo lexical do seu texto, agora ele irá revisar a parte estrutural, estética e de padronização do seu texto, procurando adequar à tipologia textual, a escrita e o vocabulário ao destinatário, assim tornando o texto mais agradável e interessante de ser lido.

Para tanto o aluno precisa revisar os seguintes aspectos:

- Tipologia textual (se o texto é um poema escrever em forma de poema, com versos, estrofes etc);

- Forma de escrita: 
- Se digitado, o aluno deve ser atentar aos ajustes do texto dentro do documento, por exemplo, utilizar o tipo de fonte determinado, padronizando a cor e o tamanho da fonte, alinhando o texto as margens direita e esquerda, cuidar ao momento da digitação para evitar erros desnecessários e do número de páginas ou linhas exigidas na orientação do texto.

- Se manuscrito, o aluno deve se atentar para o tipo de papel (evitando papéis muito coloridos), a escrita de uma letra legível e bem feita, alinhamento do texto junto às margens, ao espaço para o início de parágrafo (espaço de $2,5 \mathrm{~cm}$ ) e cuidar para não ultrapassar o número de caracteres, linhas ou páginas determinados para o texto.

- Colocação de referências e citações de acordo com as regras da ABNT;

- Usar algum tipo de destaque para palavras estrangeiras, como itálico, negrito ou sublinhado;

\section{EXEMPLO DE DINÂMICA DE REVISÃO DE TEXTO}

O ensino de língua portuguesa apresenta várias problemáticas quanto a forma com a qual o professor passa o conteúdo para o aluno, ou seja, o professor deveria fazer mais que transmitir regras gramaticais, mas também deveria desenvolver métodos e dinâmicas que consigam chamar a atenção do aluno e ao mesmo tempo ensinar a matéria, com isso contribuindo para um aprendizagem mais completa e significativa para o aluno.

A partir dessa perspectiva apresentada na entrevista transcrita acima serão apresentadas ideias de como inserir a revisão nas aulas de língua portuguesa.

\section{Dinâmica de Âncora de Jornal Televisivo}

Faixa etária: acima de 8 anos

Objetivos:

- Estimular e desenvolver a produção e a revisão textual;

- Explicar os critérios de revisão para grupos menores de alunos e aplicando a teoria em um texto dos próprios alunos;

- Promover interação e o respeito dos alunos para com a atividade de revisão textual. 
Participantes: 02 a 04

Duração: 2 a 4 aulas

Preparação:

- Atividades do professor:

- Criar notícias inéditas e fictícias;

○ Explicar gêneros textuais, principalmente, jornal e notícia;

- Apresentar vídeo de jornais televisivos brasileiros e estrangeiros;

○ Criar orientações para guiar os alunos em suas produções textuais e na fala;

- Determinar como o vídeo deverá ser produzido, a vestimenta, a linguagem, o tempo de duração etc;

○ Explicar importância de usar norma padrão da língua em jornais televisivos.

- Atividade dos alunos:

○ Formar grupos para produção do texto e vídeo;

- Conhecer as normas de gramática tradicional;

Desenvolvimento:

$1^{\circ}$ passo:

- O professor apresenta as notícias inéditas e/ou fictícias para seus alunos;

- Tempo para que os alunos dividam os grupos e escolham um tema um tema;

- Orienta os alunos quanto à forma que devem desenvolver um texto que noticiem o tema escolhido;

- Mostra aos alunos como tal texto deve ser lido no vídeo, através da explicitação de um vídeo de jornal televisivo.

$2^{\circ}$ passo

- O professor deve pedir que o texto seja confeccionado pelo grupo em sala de aula; 
- Após escreverem a notícia, os alunos devem procurar o professor para receberem orientação quanto aos critérios que irão usar para achar e solucionar os problemas do texto;

- No final de tal orientação do professor sobre revisão textual, o educador deve instruilos a praticar a mesma atividade posteriormente em casa e individualmente, e também durante a gravação do vídeo e em grupo;

$3^{\circ}$ passo

- Os alunos em momento posterior a aula devem se reunir para gravarem o vídeo com o jornal (é importante que o professor de aos alunos 5 minutos para decidirem como e onde gravarão o vídeo);

- O professor também deve orientar os alunos para que controlem e tente monitorar suas falas durante a gravação, pois eles precisam falar de acordo com a norma culta, para tanto é interessante que visualizem vídeo de vários jornais televisivos para que tenham noção sobre como se comportarem e se pronunciarem.

Cronograma:

- Uma aula para que os alunos discutam o seu tema para notícia e iniciem a produção textual;

- Uma aula para que os alunos tirem dúvida com o professor e para que o grupo discuta o que se possa melhorar no texto;

- Uma ou duas aulas para apresentação dos vídeos.

- É importante que o professor oriente os alunos para que no momento da gravação os colegas ouvintes fiquem atentos a possíveis problemas de coesão, coerência, pontuação, entre outros.

\section{CONSIDERAÇÕES FINAIS}

A presente pesquisa buscou desenvolver uma discussão sobre como a adoção de práticas de revisão textual como metodologia de ensino da Língua Portuguesa pode ser útil para o desenvolvimento cognitivo e social do aluno, uma vez que, um aprendiz que compreenda seu texto, sua fala e sua língua materna, terá obviamente mais facilidade para 
formular um bom texto e entender o porquê das diferenças existentes na língua, na fala e na escrita.

Assim, um aluno que seja consciente da sua língua gramatical, semântica e sintaticamente, além de ser capaz de produzir bons textos, também saberá como analisar e criticar o próprio texto, ou seja, o aluno será tanto autor quanto revisor do seu escrito. O aluno será revisor, porque ele analisará seu texto em vários aspectos, tais como: semântica, coesão, coerência, destinatário, tipo textual, concordâncias, estruturas gramaticais etc. Ou seja, o aluno não irá apenas corrigir os erros presentes no texto, mas também irá revisar, reler, refazer e melhorar o seu escrito.

Um dos objetivos deste trabalho foi discutir a necessidade de instruir o profissional da área de educação, sobre como criar metodologias para ensinar revisão aos alunos e critérios para avaliar a produção deles, de forma impessoal e eficiente. No intuito de mostrar que para que o aluno venha a corrigir e melhorar seu próprio texto, antes é preciso que ele tenha uma boa estruturação sobre como fazer tal atividade, e para adquirir tal conhecimento é necessária à orientação de um profisssional competente.

A ideia de que o ensino de gramática, de revisão textual, de redação entre outros também foi debatida no sentido de pontuar que tais disciplinas precisam de novas técnicas metodologias, dinâmicas etc para melhorar a aprendizagem do conteúdo, uma vez que, muitos professores ainda utilizam apenas a técnica de apresentar regras gramaticais, por exemplo, e aplicar em frases soltas. De tal modo, o aluno não apreenderá o conteúdo de forma plena, sistematizada e efetiva, assim podendo vir a ter dificuldades no momento de elaborar ou reescrever um texto.

Portanto, é fundamental que o aluno seja orientado na escola a interagir com atividades cotidianas que envolvam a escrita e a leitura, pois através deste contato o aluno poderá enxergar sua língua e o que aprendeu nas aulas de português em sua efetividade plena, ou seja, no seu cotidiano, nos texto que ele realmente lê e escreve. Assim, o aluno perceberá a importância de conhecer sua língua materna para entender e se fazer entendido na sociedade atual, que é movida tanto pela norma escrita quanto pela fala.

Os critérios apresentados nesse artigo para ensinar revisão textual devem ser adaptados a cada série e nível da turma para que sejam efetivos na aprendizagem dos alunos. O intuito dos critérios é orientar o aluno sobre o que ele deve observar no texto e procurar corrigir ou melhorar, ou seja, nortear o aluno-revisor sobre executar a atividade de revisar um texto, seja o seu próprio ou outro texto escolhido pelo professor. 
A dinâmica apresentada tem por intuito ser uma forma alternativa e interativa para se ensinar e praticar a atividade de revisão com os alunos, estudando não só os critérios de revisão do texto escrito, mas também analisando formas de melhorar o texto na fala. Tal atividade ainda pode auxiliar o professor a conscientizar os alunos sobre a necessidade de se escrever de acordo com a norma culta da língua, e em certas ocasiões monitorar a fala, usando-a também na norma padrão.

A pesquisa teve o objetivo de estudar as formas de ensino de revisão existente na literatura brasileira e também estrangeira, visando informar a necessidade do ensino de revisão no meio escolar e criar critérios e bases para guiar professores sobre como trabalhar tal assunto na sala de aula. Assim, acentua-se a ideia da necessidade do ensino de revisão de texto como uma matéria interdisciplinar dentre as disciplinas de língua portuguesa (gramática, redação, literatura e texto).

\section{BIBLIOGRAFIA}

BRASIL, MEC. Secretaria de Educação Fundamental. Brasília, 1997. Parâmetros curriculares nacionais: língua portuguesa/Secretaria de Educação Fundamental. - Brasília: MEC/SEF; 144p. Disponível em: http://portal.mec.gov.br/seb/arquivos/pdf/livro02.pdf. Acesso em: 25 maio 2011.

BRASIL, MEC. Secretaria Fundamental. Parâmetros Curriculares Nacionais - Língua Portuguesa. Brasília, 1998. Parâmetros curriculares nacionais: terceiro e quarto ciclos do ensino fundamental: língua portuguesa/Secretaria de Educação Fundamental. Brasília: MEC/SEF. Disponível em: http://portal.mec.gov.br/seb/arquivos/pdf/portugues.pdf. Acesso em: 25 maio 2011.

BRASIL; MEC (POSSENTI, S.; CAVALCANTI, J; MIQUELETTI, F.; FRANCHI, G.) 2008. Reescrita de textos: Sugestões de trabalho. Linguagem e letramento em foco. [s.l. : s. n.]. São Paulo: $\mathrm{MEC} / \mathrm{SEF}$. Disponível em: http://www.iel.unicamp.br/cefiel/alfaletras/biblioteca_professor/arquivos/62Reescrita_de_text o.pdf. Acesso em: 26 maio 2011.

BRASIL; MEC. 2001. Programa de Formação de Professores Alfabetizadores. Módulo 2. [s.l. $\quad$ s. $\quad$ n.]. Brasília: MEC/SEF. Disponível em: http://portal.mec.gov.br/seb/arquivos/pdf/Profa/col_2.pdf. Acesso em: 24 set. 2011. COÊLHO, S. A revisão como parte do processo de produção textual: o aluno/escritor como 
revisor de seus próprios textos. BDJur, Brasília, DF, 13 jul. 2009. Disponível em: $<$ http://bdjur.stj.gov.br/dspace/handle/2011/22927>. Acesso em: 24 set. 2011.

FERREIRA, A. Miniaurélio Eletrônico versão 5.12. Brasil: Positivo, 2004.

FERRONATO, V. A fala e a escrita em questão: retextualização. Associação de Leitura do Brasil. [s.1. : $\quad$ s. n.]. Curitiba: 2007. Disponível em: http://alb.com.br/arquivomorto/edicoes_anteriores/anais16/sem10pdf/sm10ss02_09.pdf. Acesso: $1^{\circ}$ out. 2011.

GUIMARÃES, S. R. K.; PAULA, F. V. de. O papel da consciência morfossintática. Educar em Revista, Curitiba, Brasil, n. 38, p. 93-111, set./dez. 2010. Editora UFPR. Disponível em: www.scielo.br/scielo.php?pid=S0104-40602010000300007\&script=sci_arttext. Acesso em: 24 set. 2011.

MENEGOLO, E; MENEGOLO, L. 2005. O significado da reescrita de textos na escola: a (re) construção do sujeito-autor. Ciências \& Cognição; Vol. 04: 73-79. Disponível em: www.cienciasecognicao.org/revista/index.php/cec/article/download/.../283. Acesso em: 26 maio 2011.

MOTA, M. O papel da consciência morfológica para a alfabetização em leitura. Psicologia em Estudo, Maringá, v. 14, n. 1, p. 159-166, jan./mar. 2009. Disponível em: www.scielo.br/scielo.php?script=sci_arttext\&pid=S1413-73722009000100019. Acesso em: 24 set. 2011.

NETO, A. Além da revisão - critérios para revisão textual. Brasília: Senac-DF, 2008.

OLIVEIRA, F. A revisão de textos como um conteúdo procedimental a ensinar na educação fundamental.

Disponível em: http: http://www.sme.pmmc.com.br/arquivos/matrizes/matrizes_portugues/anexos/texto-12.pdf Acesso em: 15 set. 2011.

SEBRANEK, P.; KEMPER, D. SkillsBook - editing and proofreading practice. Massachusetts: 2005. 